Max-Planck-Institut für demografische Forschung

Max Planck Institute for Demographic Research

Konrad-Zuse-Strasse $1 \cdot$ D-18057 Rostock · GERMANY

Tel +49 (0) 3812081 - 0; Fax +49 (0) 3812081 - 202;

http://www.demogr.mpg.de

MPIDR WORKING PAPER WP 2008-015

MARCH 2008

\title{
Marriage formation as a process intermediary between migration and childbearing
}

Jan M. Hoem (hoem@demogr.mpg.de)

Lesia Nedoluzhko

(C) Copyright is held by the authors.

Working papers of the Max Planck Institute for Demographic Research receive only limited review. Views or opinions expressed in working papers are attributable to the authors and do not necessarily reflect those of the Institute. 


\title{
Marriage formation as a process intermediary between migration and childbearing
}

\author{
Reflexions by Jan M. Hoem and Lesia Nedoluzhko, \\ Max Planck Institute for Demographic Research, Rostock, Germany
}

\begin{abstract}
In studies of differences in fertility between migrants and non-migrants, marriage interferes because migration can be motivated by an impending marriage or can entail entry into a marriage market with new opportunities. One would therefore expect elevated fertility after migration, although a competing theory states that on the contrary fertility ought to be reduced in the time around the move because migration temporarily disturbs the life of the migrant. In any case marriage appears as a process that is intermediary between migration and childbearing.

To handle such issues it pays to have a technique that allows the analyst to separate any disruptive effects of migration from any boosting effects of marriage in studies of childbearing. The purposes of the present paper is (i) to remind us that such a technique is available, in fact is straightforward, and (ii) to apply the technique to further analyze a set of data on migration and first-time parenthood in Kyrgyzstan recently used by the second author and Gunnar Andersson. The technique has the neat feature that it allows us to operate with several "clocks" at the same time. In the analysis of first births we keep track of time since migration (for migrants) and time since marriage formation (for the married) beside the respondent's age (for women at childbearing ages); in other connections there may be more clocks. For such analyses we make use of a flexible graphical housekeeping device that allows the analyst to keep track of a feature like whether migration occurs before or after marriage, or at the same time. This is a half-century-old flow chart of statuses and transitions and is not much more complex that the famous Lexis diagram, which originated with Gustav Zeuner, as we now know. These reflexions were first presented at a symposium dedicated to Professor Zeuner. ${ }^{1}$
\end{abstract}

${ }^{1}$ The Leopoldina symposium "Recent Challenges for Statistics in the Biosciences - 100 years after Gustav Zeuner", Technische Universität Bergakademie Freiberg, Germany, January 9-11, 2008. 


\section{Introduction}

In a recent study of the impact of internal migration on entry into parenthood in Kyrgyzstan, Nedoluzhko and Andersson (2007) (hereafter called N \& A) found that the impact of the recorded cause of migration on a migrant's first-birth hazard was only moderate except when the move was reported to have been made for marriage formation. Migration said to be for work, for study, to move with parents or family, or for some "other" reason, all roughly gave the same subsequent first-birth intensity, ceteris paribus, but people who moved for marriage had over three times as high a risk. (For a non-migrant the risk was around $1 / 4$ higher than for the migrant who moved for some cause other than marriage formation.) When they ran a different model with marital status (married vs. not married) as a time-varying covariate instead of the cause of migration, married individuals turned out to have a first-childbearing risk as much as 30 times as high as unmarried individuals with similar characteristics. We see that marriage was an overwhelming prerequisite for parenthood in the study population. In the present brief paper we argue that one gets a better representation of the dynamics of the behavior if marriage is drawn into the analysis as an individuallevel process in its own right and not just handled as a cause of migration or as a timevarying covariate.

To see how this can be done, consider the flow chart in Figure 1, where annotated boxes represent statuses and arrows stand for possible transitions between them. When we number the statuses from 0 to 4 , as indicated, the transitions $0 \rightarrow 2$ and $1 \rightarrow 3$ represent marriage formation before and after migration, respectively, and the transitions $0 \rightarrow 1$ and $2 \rightarrow 3$ represent migration before and after marriage. The transition $0 \rightarrow 3$ represents a simultaneous change on both of these dimensions. Entry into State 4 corresponds to a first birth. For simplicity we only include first marriage and censor observations on marriage disruption. Extension to repeated marriage is straightforward. On any later migration the respondent is moved to an extended state space with the same transition intensities as in Figure 1.

For each of the possible transitions from any state $i$ to any other state $j$ there is some intensity (or hazard) $\mu_{i j}$. We do not make it explicit in the notation, but each intensity depends on the individual's age $t$ and on a selected set of fixed and timevarying covariates, like ethnicity, place of birth, employment status, and so on. If we wanted to, we could study the marriage intensities $\mu_{02}$ and $\mu_{13}$ or the migration intensities $\mu_{01}$ and $\mu_{23}$ as well as the intensity $\mu_{03}$ of migrating and marrying simultaneously; in fact we have done so but aim to report it elsewhere. In order not to disturb our main message, we concentrate on the first-birth intensities $\varphi_{0}=\mu_{04}$, $\varphi_{1}=\mu_{14}, \varphi_{2}=\mu_{24}$, and $\varphi_{3}=\mu_{34}$, which we have marked in the diagram. The simple geometry of the state space in Figure 1 and the closer specification of these four intensity functions are the keys to a technique that allows us to handle the interplay between the three individual-level processes of migration, marriage, and childbearing. Age $t$ attained will serve as process time.

Statuses-and-transitions charts like the one in Figure 1 have been around for at least half a century and they are used in a number of disciplines for situations where there is some virtue in keeping track of several individual-level behavioral processes at the same time. The oldest appearance that we know of is a model for sickness, recovery, relapse, and death in a famous paper by Fix and Neyman (1951). The same schema is known to actuaries as the disability model (van Klinken 1959, Wolthuis 1994) and it has roots going back for over a hundred years (Karup 1893, Spangenberg 
1911, Du Pasquier 1912/1913; for a version akin to Fix and Neyman, see Sverdrup 1965). The device has been used in demography (Hoem, e.g. 1970, 1976, 2001;

Gomez de Leon and Potter 1989; Courgeau and Lelièvre 1989, 1992; Hinde 1998), in sociology (e.g., Tuma and Hannan 1984), in clinical medicine (e.g., Tolley et al. 1978, Manton and Stallard 1988), and in many other settings (e.g., Schweder 1970,

Andersen 1985, Blossfeld and Rohwer 1995). We now show how this device can also be used to handle the operation of several time schedules ("clocks") simultaneously.

0

1

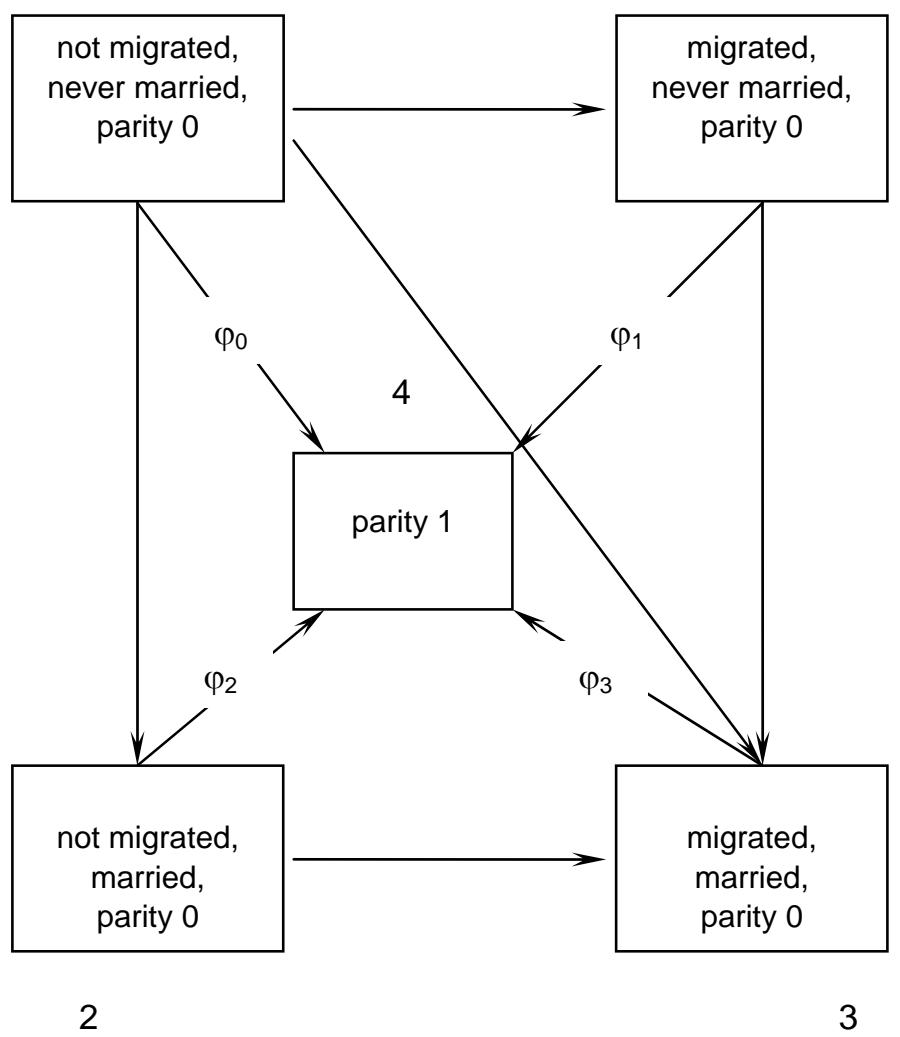

Figure 1. Flow chart with basic statuses (boxes) and transitions (arrows)

\section{Data}

In their study of the connection between migration and childbearing, $\mathrm{N} \& \mathrm{~A}$ (2007) used data from a survey called "Marriage, fertility, and migration in Kyrgyzstan”, conducted in 2005. In the survey, interviews were obtained with 756 men and 772 women at ages between 18 and 29. We use the same data and focus on the first birth (and later on the first conception) after age 15. Since men and women have such different childbearing patterns, we use the data for women only in this paper. For more details than what follows, and for an account of the setting in Kyrgyzstan, please consult N \& A (2007) and a forthcoming paper by Nedoluzhko.

In the survey, information was collected about fixed features like ethnicity and date of birth as well as complete retrospective histories of parenthood, marriage, migration, education, and employment. All dates are given to the accuracy of a month. For recorded migration the origin and destination of the move was obtained, as was 
the cause of migration ("moved with parents/family", "moved to marry", for work, for study, or for "other reasons”).

Most of these covariates are pretty straightforward and probably need no further commentary beyond the specifications that appear in what follows, but the covariate we call ethnicity may need some explanation. For the analysis this covariate is coded as "European”, “russified Asian”, and "non-russified Asian”. Following Agadjanian and Qian (1997) we call Asians russified if they mostly communicate in Russian outside of their homes. Non-russified Asians mostly speak other languages than Russian outside of home, mainly Kyrgyz. The Kyrgyz and Russians comprise an absolute majority (of around 90\%) in the "Asian" and "European" subgroups of the study population, respectively. The idea to test the role of ethnicity as a background characteristic responsible for differentials in demographic behavior comes from previous research by N \& A and their predecessors (Manning and Landale 1996, Agadjanian and Qian 1997, Agadjanian 1999, Katz 2001, Manning 2002, Agadjanian and Makarova 2003, Agadjanian et al. forthcoming). Ethnic differentials in demographic behavior, and particularly in fertility, can arise from group-specific differences in cultural values, norms and attitudes, and can reflect specific adjustment strategies developed by ethnic minorities. What we call 'russification' reflects the environment that individuals are exposed to, in that russified Asians are the most likely to communicate with Russians and are likely to live in the capital or in the surrounding region (especially in small towns of that region), where most Europeans reside. The importance of language (or rather the role of norms, values, and statuses associated with the language) in shaping demographic behavior has been emphasized again in a number of recent studies, e.g. by Finnäs (1997), Wetherell and Plakans (1997), and Yavuz (2006).

Individuals who had died before the interview or had left the country permanently after age 18, could not be interviewed of course, so our data are subject to an element of selectivity by virtue of survival in the study population (Ryder, 1965), the way survey data always are. As usual we shall not address any consequences of this feature, nor shall we pay attention to the oversampling made of ethnic minorities and of the underrepresented gender where there turned out to be a gender imbalance in the cluster sampling. Our interest is focused on other features of the data and of the analysis.

\section{Technique and results for first births}

In preparation of the specification of a simultaneous model of the four childbearing intensities $\varphi_{h}(h=0,1,2,3)$, let us define $T_{M}$ as a respondent's age at marriage and let $T_{G}$ be the age at which she makes her first geographical move. This allows us to specify a generic first-birth intensity as follows:

$$
\ln \varphi(t)=y(t)+z_{M}\left(t-T_{M}\right)+z_{G}\left(t-T_{G}\right)+\text { more },
$$

where $y(t)$ is the logarithm of a baseline intensity picking up the effect of age $t, z_{M}$ represents the effect of time since marriage, $z_{G}$ represents the effect of time since first migration, and "more" represents the effects of other covariates, fixed and timevarying. (To make sure that $T_{M}$ and $T_{G}$ are defined for all respondents, let us give either one of them the value 99999 years, say, for a respondent for whom the corresponding event was not recorded in our data.) The two functions $z_{M}$ and $z_{G}$ are specified to have the value zero for negative arguments, i.e., $z_{M}(\tau)=0$ for negative $\tau$, 
and similarly for $z_{G}$. Since this means that $z_{M}\left(t-T_{M}\right)=0$ for $t<T_{M}$ and $z_{G}\left(t-T_{G}\right)=0$ for $t<T_{G}, z_{M}$ and $z_{G}$ are called "kick-in" functions in the parlance of Lillard and Panis (2003), the idea being that they "kick in" at the process time when their respective starting event occurs, while they have no effect before that time.

The formula (1) is a compact form of the following specification:

$$
\left\{\begin{array}{l}
\ln \varphi_{0}(t) \\
\ln \varphi_{1}(t) \\
\ln \varphi_{2}(t) \\
\ln \varphi_{3}(t)
\end{array}\right\}=\left\{\begin{array}{c}
y(t)+\text { more, } \\
y(t)+z_{G}\left(t-T_{G}\right)+\text { more }, \\
y(t)+z_{M}\left(t-T_{M}\right)+\text { more, and } \\
y(t)+z_{M}\left(t-T_{M}\right)+z_{G}\left(t-T_{G}\right)+\text { more. }
\end{array}\right\}
$$

In this manner $\varphi_{0}(t)$ is made to depend on age $t$ attained, $\varphi_{1}(t)$ depends on age $t$ and on time $t-T_{G}$ since migration, $\varphi_{2}(t)$ depends on age and on time $t-T_{M}$ since marriage, and finally $\varphi_{3}(t)$ depends on all three clocks. If a respondent migrated and married at the same time (i.e., in the same month in our data), she has $T_{M}=T_{G}$.

Note that the functions $y, z_{M}$, and $z_{G}$ are the same for all $\varphi_{h}$, and we reckon that so is the quantity "more", which for instance may have the form

$$
\text { more }=\sum_{k} \alpha_{k} x_{k}+\sum_{\ell} \beta_{\ell} w_{\ell}(t),
$$

where each $x_{k}$ is a fixed covariate and each $w_{\ell}(t)$ is a time-varying covariate. While this may gloss over some differentials, it lets us detect main patterns of behavior.

Following Lillard and Panis (2003) we have used linear splines for $y, z_{M}$, and $z_{G}$ when we have fitted the first-birth intensity to our data, mainly because such functions are suitably flexible to pick up the main traits of the effects they represent. (Like N \& A we could have used piecewise constant functions instead.) The function $z_{M}$ picks up the effects both of the existence and of the duration of any marriage, and $z_{G}$ functions correspondingly for migration.

As an experiment we have left out the kick-in functions in Model 1a of Table 1. Note how much higher fertility non-russified Asian women appear to have than European women and than russified Asian according to this model. A comparison with Model 1b, which includes the kick-in splines, shows that this apparently elevated fertility is a compositional effect which disappears when proper attention is paid to marriage formation.

Figure 2b contains a plot of the two kick-in splines. (There is no Figure 2a; we call the spline-function diagram Figure $2 b$ in imitation of the model number.) As we see, the spline $z_{M}$ in Model $1 \mathrm{~b}$ has a single node at 12 months after marriage formation and $z_{G}$ has two nodes, one at 24 months after migration and one at 36 months. We have experimented with more nodes and with moving the nodes to different locations, but this has not given substantively different results. Figure $2 \mathrm{~b}$ shows that married women have much higher fertility than other women, by a factor as much as around 40 twelve months after marriage formation. (The max-point on the curve for $z_{M}$ is $e^{3.68}=39.7$.) The lower curve in the figure shows that childbearing is 
increased considerably for the first year-and-a-half after migration and also that there is a maintained moderate "super-risk" of childbearing for up to four years after the move.

For comparison with N \& A we have also fitted a standard proportionalhazards model with marital status as a time-varying covariate and with migration experience represented in a similar manner (our Model 2 in Table 1). This model is very close to what $\mathrm{N} \& \mathrm{~A}$ used as Model 2 in their appendix, but we only use the data for women and we include fewer covariates, so our coefficient estimates are somewhat different from theirs. With marital status at age $t$ as one of the $w_{\ell}(t)$ and with migration experience as another such covariate, the intensity model has the form $\ln \varphi(t)=y(t)+\sum_{k} \alpha_{k} x_{k}+\sum_{\ell} \beta_{\ell} w_{\ell}(t)$. There are no kick-in splines, and this experimental model does not take into account duration since marriage or since migration. We get a relative risk of about 17 for women in their first marriage (as compared to never-married women, ceteris paribus). This is some kind of average of the exponentiated ordinates on the curve for $z_{M}$ in Figure $2 \mathrm{~b}$, which range between 4.5 and 40, approximately. We note that the other coefficient estimates in this model are roughly the same as in Model 1b; in particular it gets the relative fertility of nonrussified Asian women right. In their main models, N \& A incorporated duration since migration in their analysis but left out duration of marriage. With the wisdom of hindsight we prefer to focus on duration of marriage.

As a final comment on our general method, let us note that we have used three "clocks" in the analysis, namely age $t$ attained, time $t-T_{G}$ since migration, and time $t-T_{M}$ since marriage. For some purposes a separate "clock" for calendar time may also be useful, though we do not employ it here. For higher-order births (which we do not address in these reflexions), one can include time since last previous birth in addition in a similar manner. (Sometimes this duration variable is used as the process time instead.)

\section{Results for first conceptions}

To facilitate comparison with $\mathrm{N} \& \mathrm{~A}$, the event whose occurrence intensity we analyze is first birth in Models 1a, 1b, and 2. This has the disadvantage that the timevarying covariates are measured at the time of (birth) occurrence, while more likely their values some months earlier are better determinants of such decisions as not to abort an unplanned pregnancy deliberately. Since the analyst does not really know when conception occurred, it is typically estimated roughly as a date nine months before the reported date of birth, or seven months before on the philosophy that the woman cannot be sure she is pregnant before a couple of months into the pregnancy, and the final decision to bear the child will only be made when she is sure. This reasoning disregards both any lead time before the conception and the possibility of a subsequent miscarriage (which we do not record); briefly it is anticipatory of the event of childbearing, in that only pregnancies that lead to a live birth are taken into account. However all this may be, we have carried out an analysis of first conceptions parallel to the one for first births in our Model 1b, counting the "date of conception" as seven months before the birth recorded. (Studying conceptions is standard demographic practice.) We have used the same model specification as in Model 1b, have listed the outcome as Model 1c in Table 1, and have plotted the kick-in splines in Figure 1c. (The numbering is made by design so that we can take ' $b$ ' to stand for "birth" and 'c' to stand for conception.) Table 1 shows that it does not much matter 
for most regression coefficients which of the two models we choose, and Figures 2b and 2c show the same for the kick-in splines, except possibly that details in the left tail of the splines in Figure 2c may seem slightly more sensible as representations of the duration effects.

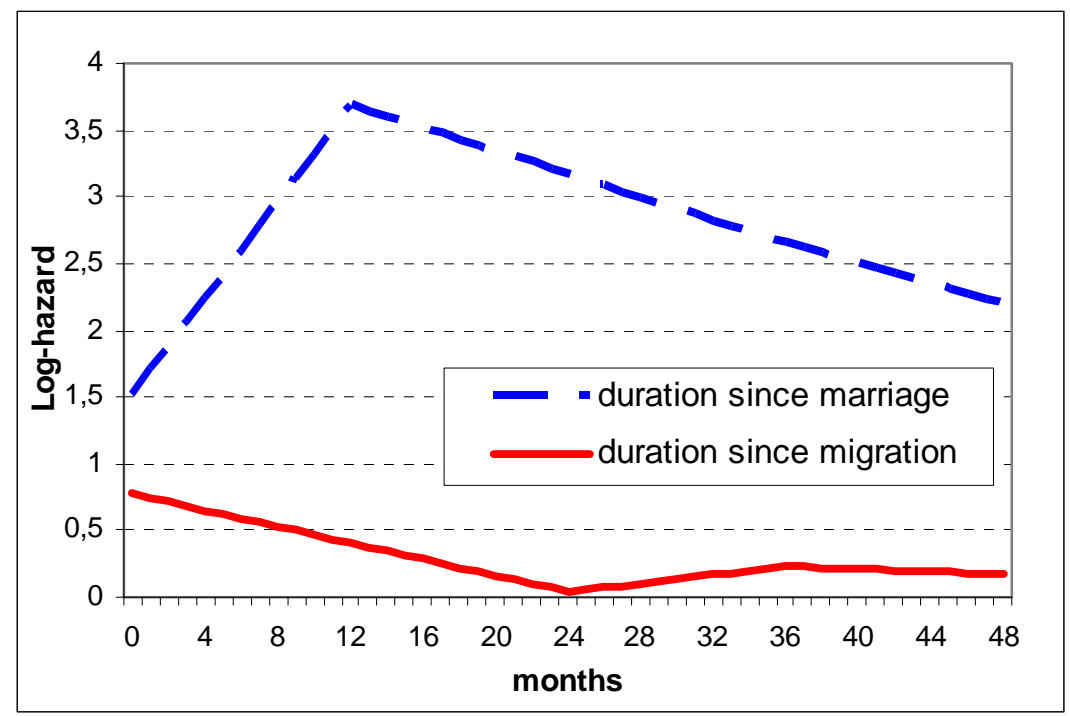

Figure 2b. Kick-in splines $z_{M}$ and $z_{G}$ in the intensity for first birth (Model 1b) by months since the initiating event (marriage or migration, respectively). Standardized for age, ethnicity, education, and employment. Women in Kyrgyzstan.

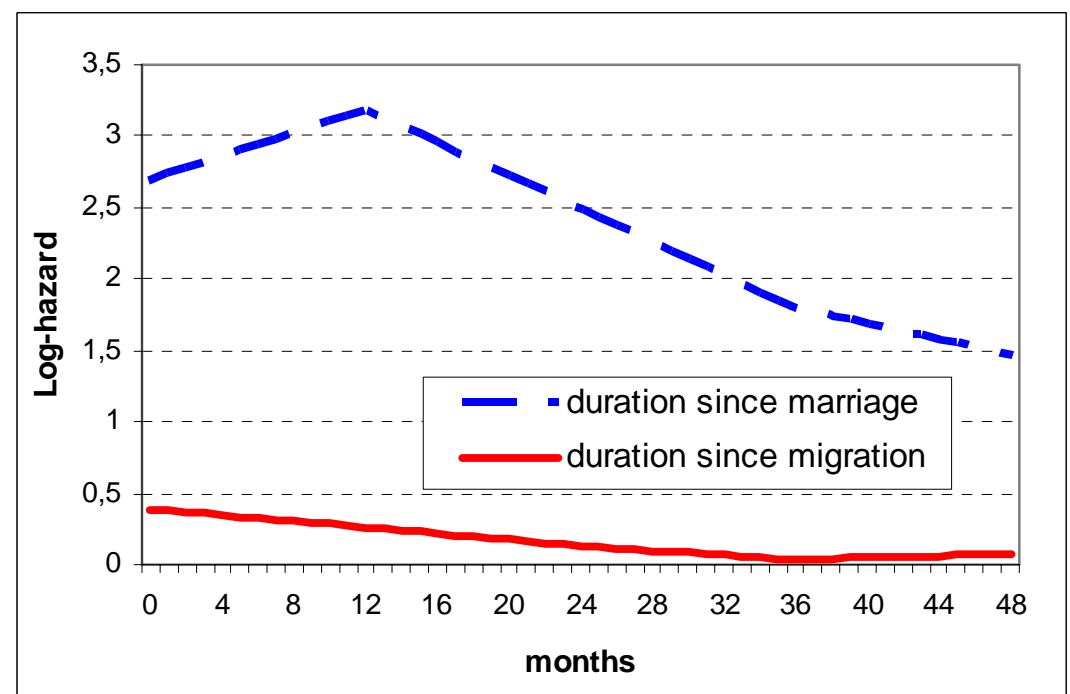

Figure 2c. Kick-in splines $z_{M}$ and $z_{G}$ in the intensity for first conception (Model 1c) by months since the initiating event (marriage or migration, respectively). Standardized for age, ethnicity, education, and employment. Women in Kyrgyzstan. 
Table 1. Relative risks in the intensity of birth/conception of the first child. Women in Kyrgyzstan

Factor

Ethnicity

European

Russified Asian

Non-russified Asian

\section{Employment}

Employed

Not employed

\author{
Relative risk
}

Model 1a Model 1b Model 2 Model 1c

\section{Educational attainment}

In education

$0.33 \quad 0.50$

0.50

0.53

Educational level completed: $\begin{array}{ll}\text { general secondary } & 1 \\ \text { vocational or higher } & 0.98\end{array}$

1

0.85

$\begin{array}{ll}1 & 1 \\ 0.87 & 0.89\end{array}$

\section{Marital status}

Never married

In first marriage

\section{Migration experience}

Not migrated

Migrated

NoTES: Model 1a. First birth, without kick-in splines for the effects of marriage and migration. Model 1b. With such splines (first birth).

Model 2. Without splines (first birth). With marital status and migration experience as time-varying covariates.

Model 1c. Model for first conceptions, with kick-in splines.

All substantial differences are strongly significant ( $\mathrm{p}=0.01$ or better).

\section{The road ahead}

One advantage with the approach we use is that it easily generates more complex intensity models. One can re-specify the expression in (3), introduce interactions at will, let the intensities $\varphi_{h}$ have separate (instead of common) kick-in splines, add the possibility of non-marital cohabitation, and so on, restricted only by the size and quality of the data set, by any underlying substantive theory taken into consideration, and by the imagination of the investigator. For the purpose of displaying the potential of the flow chart the most interesting extension is to subdivide transitions from State 3 to State 4 in Figure 1 according to mode of entry into State 3, as indicated in Figure 3. The single first-birth intensity $\varphi_{3}$ will then be replaced by three intensities, called $\varphi_{3 a}, \varphi_{3 b}$, and $\varphi_{3 c}$, say, defined according to whether marriage occurred before or after migration, or at the same time. This flexibility of the flow chart allows us to pick up a variant of theories frequently found in work on the connection between migration and fertility. 
This connection is regularly described by hypotheses about socialization, adaptation, selectivity, and disruption. The socialization hypothesis posits that the fertility of migrants is influenced by preferences formed during early socialization and therefore is colored by the childbearing behavior of the sending population. The adaptation hypothesis says that migrant fertility depends rather on factors related to the receiving population. The selection hypothesis suggests that migrants have characteristics that are conducive to migration and that also impact on childbearing behavior. Finally the disruption hypothesis stipulates that their fertility is reduced in the time around the move because migration temporarily disturbs the life of the migrant. N \& A test these hypotheses with their data.

In the spirit of such theories one might hypothesize

(i) that respondents who married before migration tend to have fertility more strongly colored by behavior in the sending population (in line with the socialization hypothesis) because presumably both partners most often come from the same setting and are likely to have some experience of marital life in this setting,

(ii) that respondents who married after migration tend to have fertility more like people in the receiving population (in line with the adaptation hypothesis), and

(iii) perhaps that respondents who moved and married in the same month tend have childbearing behavior temporarily more strongly disturbed by the move than others (in line with the disruption hypothesis) or conversely that they often moved because they wanted/expected a child soon and therefore have elevated fertility after the change-over (in line with a hypothesis of positive selection).

Whatever the underlying theory may be, we have estimated $\varphi_{3 a}, \varphi_{3 b}$, and $\varphi_{3 c}$ separately (using separate kick-in splines) but have found no essential difference between the three of them nor between any one of them and the birth intensity $\varphi_{2}$ of the married non-migrants. (Further details of these empirical comparisons will be provided elsewhere.) We suppose that either the distinctions are not strong in reality, or perhaps that the data set is too small to support such distinctions. We also believe that one needs to draw in more information than what we have done, particularly data on the origin and destination of the moves (which we have available but have not used in this paper), or even better: data on the geographical location of the marriage partner. (If both partners lived in the sending population before marriage, they are perhaps more likely to conform to its behavior than if they lived in separate locations.) If it turns out that we need to study each combination of regions of origin and destination, there will be $r(r-1)$ separate analyses when there are $r$ regions. (N\&A operate with three regions, and this alone may give up to six connected analyses.) Most likely such subdivision would highlight the need for a bigger data set even more strongly, however, and we are not prepared to pursue these ideas at the present stage. We leave it to future research based on more extensive data sets to assess the value of existing migration theory. We believe that our set-up will prove to be a useful tool in such an assessment. Meanwhile we regard these experiments as a check on the goodness of fit of the more parsimonious model (2). 


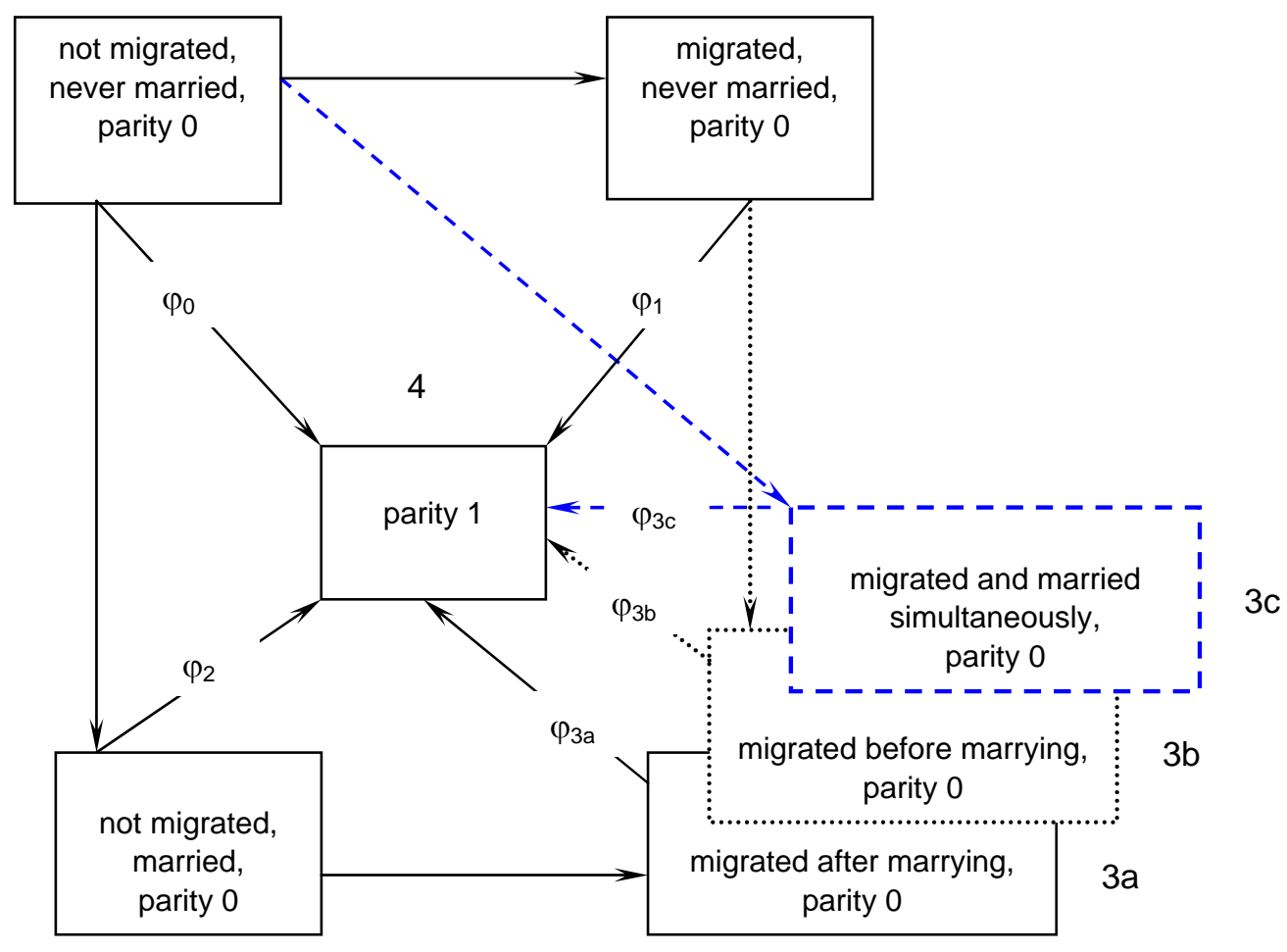

2

\section{Figure 3. Flow chart with subdivision of State 3 according to the timing of marriage relative to migration}

\section{Discussion}

The main purpose of the present reflexions is to provide a reminder of the usefulness and flexibility of a simple flow chart of the kind displayed in Figures 1 and 3. Our particular application shows how one can easily make the role of an intermediary process (marriage formation) explicit in a situation where interest so far has focused on how one behavioral process (migration) influences another behavioral process (childbearing) while the third process only lurks in the background and "disturbs" the relationship between the first two processes. We have described how such a situation can be analyzed with confidence and how intellectual control is maintained by means of the flow chart, which can also serve as a vehicle for further development of the models involved. Despite the fact that the flow chart has been on the books for half a century or more, it still deserves more attention than it normally gets in current empirical research.

Investigators may not always have been interested in (or aware of) such an analytic approach, where a feature is decomposed into its constituent parts. Their purpose may rather have been to find the total effect of migration on fertility, much as an epidemiologist may sometimes not (or not only) want to assess direct and indirect effects but aim to establish total effects. (For recent contributions to the flowering literature on these issues in epidemiology, see Pearl 2001, Petersen et al. 2006, Didelez 2007, 2008, and Fosen et al. 2006ab. Fosen et al. 2006b contains a particularly instructive worked-out example.) A clarification in the spirit of such contributions needs to sort out not only the causal relations between migration, marriage, and childbearing, but also to draw in the covariates from our models, and in particular to incorporate our time-varying covariates as behavioral processes in their 
own right, much as we have done here for marriage formation. Venturing further into such waters must wait for another occasion, however.

\section{Acknowledgements}

The second author is grateful to the Max Planck Institute for Demographic Research (MPIDR) for financial support and for having made its facilities available as needed. The authors are grateful to Victor Agadjanian for his permission to use data from the survey 'Marriage, Fertility, and Migration in Kyrgyzstan', and to the National Council for East European and Eurasian Research, USA, for funding that survey. Both authors appreciate useful comments from Gunnar Andersson. We also thank the organizers of the 2008 Zeuner Symposium (Dietrich Stoyan and Niels Keiding) for providing us with a forum to discuss a draft of this paper. We appreciate the feedback that we got, particularly from Niels Keiding, Vanessa Didelez, and Andreas Stang.

\section{References}

Agadjanian, V. and Qian, Z.C. (1997). Ethnocultural identity and induced abortion in Kazakstan. Studies in Family Planning 28 (4): 317-329 DEC 1997

Agadjanian, V. 1999. Post-soviet demographic paradoxes: Ethnic differences in marriage and fertility in Kazakhstan. Sociological Forum 14 (3): 425-446.

Agadjanian, V. and Makarova, E. (2003). From Soviet modernization to post-Soviet transformation: Understanding marriage and fertility dynamics in Uzbekistan. Development and Change 34 (3): 447-473.

Agadjanian, V., Nedoluzhko, L., and Kumskov, G. (2008). Eager to leave? Intentions to migrate abroad among young people in Kyrgyzstan. International Migration Review (forthcoming).

Andersen, P. K. (1985). Statistical models for longitudinal labor market data based on counting processes. In J. J. Heckman and B. Singer (Eds.), Longitudinal analysis of labor market data, pp. 294-307.

Blossfeld, H.-P. and Rohwer, G. (1995). Techniques of event history modeling. New approaches to causal analysis. Lawrence Erlbaum, Mahwah, NJ.

Courgeau, D. and Lelièvre, É. (1989). Analyse démographique des biographies. Éditions INED, Paris.

Courgeau, D. and Lelièvre, É. (1992). Event history analysis in demography. Oxford: Clarendon Press.

Didelez, V. (2007). Graphical models for composable finite Markov processes. Scandinavian Journal of Statistics 34, 169-185.

Didelez, V. (2008). Graphical models for marked point processes based on local independence. Journal of the Royal Statistical Society, Series B 70 (1), 245264.

DuPasquier, L. G. (1912 and 1913). Mathematische Theorie der Invaliditätsversicherung. Mitteilungen der Vereinigung schweizerischer Versicherungsmathematiker 7, 1-7, and 8, 1-153.

Finnäs, F. (1997). Social integration, heterogeneity and divorce. The case of the Swedish-speaking population in Finland. Acta Sociologica 40: 263-277.

Fix, E. and Neyman, J. (1951). A simple stochastic model of recovery, relapse, death and loss of patients. Human Biology 33 (3), 205-241. 
Fosen, J., Borgan, Ø., Weedon-Fekjær, H., and Aalen. O.O.(2006a). Dynamic analysis of recurrent event data using the additive hazard model. Biometrical Journal 48 (3), 381-398.

Fosen, J., Ferkingstad, E., Borgan, Ø., and Aalen, O.O. (2006b). Dynamic path analysis - a new approach to analyzing time-dependent covariates. Lifetime Data Analysis 12, 143-176.

Goméz de León, J. and Potter, J. E. (1989). Modelling the inverse association between breastfeeding and contraceptive use. Population Studies 43, 69-93.

Hinde, A. (1998). Demographic methods. Arnold, London etc.

Hoem, J. M, (1970). A probabilistic approach to nuptiality. Biometrie, Praximetrie 11 (1), 3-19.

Hoem, J. M. (1976). The statistical theory of demographic rates - a review of current developments. Scandinavian Journal of Statistics 3, 169-185.

Hoem, J. M. (2001). Demographic analysis: Probabilistic approach. In Smelser, N.J. and Baltes, P.B. (2001), International Encyclopedia of the Social \& Behavioral Sciences 5, 3428-3432.

Karup, I. (1893). Die Finanzlage der Gothaischen Staatsdiener-Wittwen-Societät. Dresden.

Katz, R. (2001). Effects of migration, ethnicity, and religiosity on cohabitation. Journal of Comparative Family Studies 32 (4): 587-599.

Lillard, L. A. and Panis, C. W. A. (2003). aML multilevel multiprocess statistical software, Version 2.0. EconWare, Los Angeles, California.

Manning, W.D. and Landale, N.S. (1996). Racial and ethnic differences in the role of cohabitation in premarital childbearing. Journal of Marriage and Family 58(1): 63-77.

Manning, W.D. (2002). First comes cohabitation and then comes marriage? A research note. Journal of Family Issues 23 (8): 1065-1087.

Manton, K.G. and Stallard, E. (1988). Chronic disease modeling: Measurement and evaluation of the risks of chronic disease processes. Charles Griffin, London.

Nedoluzhko, L. and Andersson, G. (2007). Migration and first-time parenthood: Evidence from Kyrgyzstan. Demographic Research 17 (25), 741-774. Download from http://www. demographic-research.org/volumes/vol17/25/.

Pearl, J. (2001). Direct and indirect effects. Proceedings of the Seventeenth Conference on Uncertainty in Artificial Intelligence, 411-420. San Francisco, Cal.: Morgan Kaufmann.

Petersen, M.L., Sinisi, S.E.; and van der Laan, M. J. (2006). Estimation of direct causal effects Epidemiology 17 (3), 276-284

Ryder, N. (1965). The measurement of fertility patterns. In Sheps, M. S. and Ridley, J. C. (Eds.), Public Health and Population Change. University of Pittsburth Press.

Schweder, T. (1970). Composable Markov Processes. Journal of Applied Probability, 7 (2), 400-410.

Spangenberg, P. (1911). Die Karupsche Theorie der unabhängigen Wahrscheinlichkeiten. Veröffentlichungen des deutschen Vereins für Versicherungswissenschaft, Heft 20.

Sverdrup, E. (1965). Estimates and test procedures in connection with stochastic models for deaths, recoveries and transfers between different states of health. Skandinavisk Aktuarietidskrift 1965, häft 3-4, 184-211.

Tolley, H.D., Burdick, D., Manton, K.G., and Stallard, E. (1978). A compartment model approach to the estimation of tumor incidence and growth: Investigation of a model of cancer latency. Biometrics 34 (3), 377-389. 
Tuma, N B. and Hannan, M T. (1984). Social dynamics: Models and methods. Academic Press, New York.

van Klinken, J. (1959). The theory of random processes and actuarial statistics: Dependent and independent probabilities. Mitteilungen der Vereinigung schweizerischer Versicherungsmathematiker 59, 139-162.

Wetherell, C. and Plakans, A. (1997). Fertility and culture in Eastern Europe: a case study of Riga, Latvia, 1867-1881. European Journal of Population 13: 243268.

Wolthuis, H. (1994). Life insurance mathematics (the Markovian model). CAIRE, Brussels (Education Series).

Yavuz, S. (2006). Completing the fertility transition: Third birth developments by language groups in Turkey. Demographic Research 15(15): 435-460. 